\title{
The Set of Fuzzy Time Series Forecasting Models Based on the Ordered Difference Rate
}

\author{
Chengguo Yin ${ }^{1}$, Hongxu Wang, ${ }^{2, *}$, Hao Feng ${ }^{3}$ and Xiaoli $\mathrm{Lu}^{2}$ \\ ${ }^{1}$ School of Ocean Information Engineering, Hainan Tropical Ocean University, Sanya, Hainan, 572022, China \\ ${ }^{2}$ School of Ocean Business, Hainan Tropical Ocean University, Sanya, Hainan, 572022, China \\ ${ }^{3}$ School of Ocean Science and Technology, Hainan Tropical Ocean University, Sanya, Hainan, 572022, China \\ ${ }^{*}$ Corresponding autho
}

\begin{abstract}
Song and Chissom established fuzzy time series forecasting model in 1993. Stevenson and Porter improved the forecasting model of Jilani, Burney, and Ardil in 2009, and researched the forecasting problem of enrollments of the University of Alabama 1971-1992. Although they obtained the best prediction accuracy by 2009 , the prediction accuracy was still not ideal. In this paper, we improved the forecasting model of Stevenson and Porter, and got the SFBODR (The Set of Fuzzy Time Series Forecasting Models Based on the Ordered Difference Rate). The forecasting model SFBODR(0.00004, 0.00003) can get the ideal state of AFER(Average Forecasting Error Rate) $=0 \%$ and MSE(Mean Square Error) $=0$ in forecasting the enrollments of the University of Alabama.
\end{abstract}

Keywords-fuzzy time series forecasting method; fuzzy number function of SFBODR; inverse fuzzy number function of SFBODR; forecasting function of SFBODR

\section{INTRODUCTION}

Song and Chissom [1-3] established the fuzzy time series forecasting model in 1993, and first researched the forecasting problem of enrollments of the University of Alabama 19711992. A great deal of fuzzy time series forecasting models emerge as the times require, but the prediction accuracy is still not high enough. These forecasting models in [6-15] are all derived from the defuzzification technology proposed by Jilani, Burney, and Ardil [14,16]. Stevenson and Porter [11] highly improved the prediction accuracy by using the improved defuzzification technology in 2009. When studying the forecasting problem of enrollments of the University of Alabama 1971-1992, they obtained the best prediction accuracy by 2009 (See Table II). The defuzzification technology sets a precedent for exploring fuzzy time series forecasting models with high prediction accuracy. In this paper, we further extend their research achievements, and propose the SFBODR(The Set of Fuzzy Time Series Forecasting Models Based on the Ordered Difference Rate). In the study of the forecasting problem of enrollments of the University of Alabama 1971-1992, the AFER(Average Forecasting Error Rate) and MSE(Mean Square Error) of predicted values of enrollments of the forecasting models SFBODR(0.00003, $0.00004)$ and SFBODR(0.00004,0.00003) are both zero.

\section{The Set OF Fuzzy Time Series Forecasting Models BASED ON THE ORDERED DIFFERENCE RATE}

This paper continues to use the relevant concepts which are used by Stevenson and Porter [11]. Assuming there is a time series forecasting problem, let $E=\left\{E_{1}, E_{2}, \ldots, E_{n}\right\}$ be the universe of discourse for historical data. The formula for calculating the year to year difference rate of historical data is $\mathrm{G}_{\mathrm{p}}=\left(\mathrm{E}_{\mathrm{p}}-\mathrm{E}_{\mathrm{p}-1}\right) / \mathrm{E}_{\mathrm{p}-1}$. The universe of discourse for the difference rate of historical data is recorded as $G=\left\{G_{2}, G_{3}, \ldots\right.$, $\left.G_{n}\right\}$. If we arrange each data in $G=\left\{G_{2}, G_{3}, \ldots, G_{n}\right\}$ from small to large, then constitute a new set $g=\left\{g_{1}, g_{2}, \ldots, g_{n-1}\right\}$, which is called the universe of discourse for the ordered difference rate of historical data.

Definition 1. Assuming there is a time series forecasting problem, let $E=\left\{E_{1}, E_{2}, \ldots, E_{n}\right\}$ be the universe of discourse for historical data, let $G=\left\{G_{2}, G_{3}, \ldots, G_{n}\right\}$ be the universe of discourse for the difference rate of historical data, and let $\mathrm{g}=$ $\left\{\mathrm{g}_{1}, \mathrm{~g}_{2}, \ldots, \mathrm{g}_{\mathrm{n}-1}\right\}$ be the universe of discourse for the ordered difference rate. The fuzzy number function $\mathrm{J}_{\mathrm{p}}\left(\mu_{1}, \mu_{2}\right)$ is defined on set $g$ as

$$
J_{p}\left(\mu_{1}, \mu_{2}\right)=\left\{\begin{array}{l}
\frac{1}{g_{1}}+\frac{\mu_{2}}{g_{2}}, \quad \text { if } \quad p=1 \\
\frac{\mu_{1}}{g_{p-1}}+\frac{1}{g_{p}}+\frac{\mu_{2}}{g_{p+1}}, \text { if } 2 \leq p \leq n-2, \\
\frac{\mu_{1}}{g_{n-1}}+\frac{1}{g_{n}}, \quad \text { if } \quad p=n-1 .
\end{array}\right.
$$

Where the independent variables $\mu_{1} \in[0,1)$ and $\mu_{2} \in[0,1)$ are also called the membership degree of $\mathrm{J}_{\mathrm{p}}\left(\mu_{1}, \mu_{2}\right)$. When $\mu_{1}=\mu_{2}=\mu$, the fuzzy number function of SFBODR is recorded as $\mathrm{J}_{\mathrm{p}}(\mu)(\mathrm{p}=1,2, \ldots, \mathrm{n}-1)$.

Definition 2. Assuming there is a time series forecasting problem, let $E=\left\{E_{1}, E_{2}, \ldots, E_{n}\right\}$ be the universe of discourse for historical data, let $G=\left\{G_{2}, G_{3}, \ldots, G_{n}\right\}$ be the universe of discourse for the difference rate of historical data, and let $\mathrm{g}=$ $\left\{g_{1}, g_{2}, \ldots, g_{n-1}\right\}$ be the universe of discourse for the ordered difference rate. If the ordered difference rate $\mathrm{g}_{\mathrm{p}}(\mathrm{p} \in\{1,2, \ldots, \mathrm{n}$ $1\})$ corresponds to the difference rate $G_{b}(b \in\{2,3, \ldots, n\})$, then the inverse fuzzy number function $\mathrm{I}_{\mathrm{p}}\left(\mu_{1}, \mu_{2}\right)$ of the fuzzy number function $\mathrm{J}_{\mathrm{p}}\left(\mu_{1}, \mu_{2}\right)$ is defined on set $\mathrm{g}$ as 


$$
I_{p}\left(\mu_{1}, \mu_{2}\right)=\left\{\begin{array}{l}
\frac{1+\mu_{2}}{\frac{1}{g_{1}}+\frac{\mu_{2}}{g_{2}}}, \quad \text { if } p=1, \\
\frac{\mu_{1}+1+\mu_{2}}{\frac{\mu_{1}}{g_{p-1}}+\frac{1}{g_{p}}+\frac{\mu_{2}}{g_{p+1}}}, \text { if } 2 \leq p \leq n-2, \\
\frac{\mu_{1}+1}{\frac{\mu_{1}}{g_{n-1}}+\frac{1}{g_{n}}}, \quad \text { if } p=n-1 .
\end{array}\right.
$$

Where the independent variables $\mu_{1} \in[0,1)$ and $\mu_{2} \in[0,1)$ are also called the membership degree of $\mathrm{I}_{\mathrm{p}}\left(\mu_{1}, \mu_{2}\right)$. When $\mu_{1}=\mu_{2}=\mu$, the inverse fuzzy number function of SFBODR is recorded as $\mathrm{I}_{\mathrm{p}}(\mu)(\mathrm{p}=1,2, \ldots, \mathrm{n}-1)$. If the ordered difference rate $g_{p}$ corresponds to the difference rate $G_{b}$ of year $b$ then $\mathrm{I}_{\mathrm{p}}\left(\mu_{1}, \mu_{2}\right)$ represents the approximation of the difference rate $G_{b}$ of year $b$.

Definition 3. Assuming there is a time series forecasting problem, let $E=\left\{E_{1}, E_{2}, \ldots, E_{n}\right\}$ be the universe of discourse for historical data, let $G=\left\{G_{2}, G_{3}, \ldots, G_{n}\right\}$ be the universe of discourse for the difference rate of historical data, and let $\mathrm{g}=$ $\left\{\mathrm{g}_{1}, \mathrm{~g}_{2}, \ldots, \mathrm{g}_{\mathrm{n}-1}\right\}$ be the universe of discourse for the ordered difference rate. For each selected $\mathrm{p} \in\{1,2, \ldots, \mathrm{n}-1\}$, the forecasting function $\mathrm{H}_{\mathrm{p}}\left(\mu_{1}, \mu_{2}\right)$ is defined as

$$
H_{p}\left(\mu_{1}, \mu_{2}\right)=E_{b-1}\left(1+I_{p}\left(\mu_{1}, \mu_{2}\right)\right)
$$

where the independent variables $\mu_{1} \in[0,1)$ and $\mu_{2} \in[0,1)$ are also called the membership degree of the forecasting function $\mathrm{H}_{\mathrm{p}}\left(\mu_{1}, \mu_{2}\right)$. $\mathrm{E}_{\mathrm{b}-1}$ is the historical data of year $\mathrm{b}-1, \mathrm{I}_{\mathrm{p}}\left(\mu_{1}, \mu_{2}\right)$ is the inverse fuzzy number function (2) of year p. When $\mu_{1}=\mu_{2}=\mu$, the forecasting function of SFBODR is recorded as $\mathrm{H}_{\mathrm{p}}(\mu)(\mathrm{p}=1,2, \ldots, \mathrm{n}-1)$. When $\mu_{1}$ and $\mu_{2}$ fetch the specific membership degree in [0,1), then $\mathrm{H}_{\mathrm{p}}\left(\mu_{1}, \mu_{2}\right)$ is called the forecasting formula of SFBODR, the forecasting formula can be also recorded as $\operatorname{SFBODR}\left(\mu_{1}, \mu_{2}\right)$. If the ordered difference rate $g_{p}$ corresponds to the difference rate $G_{b}$ of year $b$, then $\mathrm{H}_{\mathrm{p}}\left(\mu_{1}, \mu_{2}\right)$ represents the predicted value of year $\mathrm{b}$.

Assuming there is a time series forecasting problem, let $\mathrm{E}=$ $\left\{E_{1}, E_{2}, \ldots, E_{n}\right\}$ be the universe of discourse for historical data, let $G=\left\{G_{2}, G_{3}, \ldots, G_{n}\right\}$ be the universe of discourse for the difference rate of historical data, and let $g=\left\{g_{1}, g_{2}, \ldots, g_{n-1}\right\}$ be the universe of discourse for the ordered difference rate. If the membership degree $\mu_{1}$ and $\mu_{2}$ fetch specific values in [0,1), a forecasting formula $\operatorname{SFBODR}\left(\mu_{1}, \mu_{2}\right)$ can be established by (3). In the study of the time series forecasting problem, the application steps are as follows:

1). Write out the historical data table of time series forecasting problem;

2). Write out the universe of discourse $\mathrm{H}$ for the historical data, the universe of discourse $G$ for the difference rate and the universe of discourse $g$ for the ordered difference rate;

3). Write out the forecasting formula $\operatorname{SFBODR}\left(\mu_{1}, \mu_{2}\right)$;
4). Use $\operatorname{SFBODR}\left(\mu_{1}, \mu_{2}\right)$ to calculate the predicted values of the historical data.

Thus, the forecasting formula $\operatorname{SFBODR}\left(\mu_{1}, \mu_{2}\right)$ is a fuzzy time series forecasting model $\operatorname{SFBODR}\left(\mu_{1}, \mu_{2}\right)$.

Definition 4. For a time series forecasting problem, let $\mathrm{E}=$ $\left\{E_{1}, E_{2}, \ldots, E_{n}\right\}$ be the universe of discourse for historical data, let $G=\left\{G_{2}, G_{3}, \ldots, G_{n}\right\}$ be the universe of discourse for the difference rate of historical data, and let $g=\left\{g_{1}, g_{2}, \ldots, g_{n-1}\right\}$ be the universe of discourse for the ordered difference rate. When $\mu_{1}$ and $\mu_{2}$ fetch each value in the semi-closed and semi-open interval $[0,1)$, infinite fuzzy time series forecasting models $\operatorname{SFBODR}\left(\mu_{1}, \mu_{2}\right)$ can be obtained. All the time series forecasting models $\operatorname{SFBODR}\left(\mu_{1}, \mu_{2}\right)$ are taken as elements, and they constitute a set, which is called SFTSFMBODR(The Set of Fuzzy Time Series Forecasting Models Based on the Ordered Difference Rate), the abbreviation is simplified as SFBODR. The general element of SFBODR is $\operatorname{SFBODR}\left(\mu_{1}, \mu_{2}\right)$. $\operatorname{SFBODR}\left(\mu_{1}, \mu_{2}\right)$ represents the forecasting formula of a fuzzy time series as well as a fuzzy time series forecasting model taking $\operatorname{SFBODR}\left(\mu_{1}, \mu_{2}\right)$ as the forecasting formula.

Theorem. For a time series forecasting problem, let $E=\left\{E_{1}\right.$, $\left.E_{2}, \ldots, E_{n}\right\}$ be the universe of discourse for historical data, let $G$ $=\left\{G_{2}, G_{3}, \ldots, G_{n}\right\}$ be the universe of discourse for the difference rate of historical data, and let $g=\left\{g_{1}, g_{2}, \ldots, g_{n-1}\right\}$ be the universe of discourse for the ordered difference rate. If the ordered difference rate $\mathrm{g}_{\mathrm{p}}(\mathrm{p} \in\{1,2, \ldots, \mathrm{n}-1\})$ corresponds to the difference rate $G_{b}(b \in\{2,3, \ldots, n\})$, for each selected $p \in$ $\{1,2, \ldots, n-1\}$, then

1). The fuzzy number function $\mathrm{J}_{\mathrm{p}}\left(\mu_{1}, \mu_{2}\right)$, inverse fuzzy number function $\mathrm{I}_{\mathrm{p}}\left(\mu_{1}, \mu_{2}\right)$, and forecasting function $\mathrm{H}_{\mathrm{p}}\left(\mu_{1}, \mu_{2}\right)$ of SFBODR are all continuous functions;

2). When $\mu_{1} \rightarrow 0$ and $\mu_{2} \rightarrow 0$, the inverse fuzzy number function $\mathrm{I}_{\mathrm{p}}\left(\mu_{1}, \mu_{2}\right)$ converges to the difference rate $\mathrm{G}_{\mathrm{b}}$ of historical data of year $b$ :

$$
\lim _{\mu_{1} \rightarrow 0, \mu_{2} \rightarrow 0} I_{p}\left(\mu_{1}, \mu_{2}\right)=G_{b}
$$

3). When $\mu_{1} \rightarrow 0$ and $\mu_{2} \rightarrow 0$, then the forecasting function $\mathrm{H}_{\mathrm{p}}\left(\mu_{1}, \mu_{2}\right)$ converges to the historical data $\mathrm{N}_{\mathrm{b}}$ of year b:

$$
\lim _{\mu_{1} \rightarrow 0, \mu_{2} \rightarrow 0} H_{p}\left(\mu_{1}, \mu_{2}\right)=N_{b} ;
$$

4). When the membership degree $\mu_{1}$ and $\mu_{2}$ are small enough, the forecasting function value $\mathrm{H}_{\mathrm{p}}\left(\mu_{1}, \mu_{2}\right)$ of SFBODR is equal to the historical data $\mathrm{N}_{\mathrm{b}}$ of year $\mathrm{b}$.

In the study of the forecasting problem of enrollments of the University of Alabama 1971-1992, Table I and II give the prediction results of the fuzzy time series forecasting models based on the defuzzification technology. The AFER and MSE of the prediction results in Table I and II are relatively small in all fuzzy time series forecasting models. Especially, Table I gives the prediction results by using SFBODR (0.00004, 
$0.00003)$ and SFBODR $(0.00003,0.00004)$ to forecast the enrollments of the University of Alabama 1971-1992; the $\mathrm{MSE}=0$ and $\mathrm{AFER}=0.0 \%$, which are the most ideal prediction accuracy.

In Table I: the formulas of MSE and AFER are:

$$
\begin{gathered}
\text { MSE }=\frac{1}{n} \sum_{b=1}^{n}\left(E_{b}-H_{b}\right)^{2} ; \\
\text { AFER }=\left(\frac{1}{n} \sum_{b=1}^{n}\left|E_{b}-H_{b}\right| / E_{b}\right) \times 100 \%
\end{gathered}
$$

\begin{tabular}{|c|c|c|c|c|c|c|c|}
\hline Year & Enrollments & $\begin{array}{c}\text { Wang, } \\
\text { Guo, } \\
\text { Feng, } \\
\text { Jin.[12] }\end{array}$ & $\begin{array}{c}\text { Wang, } \\
\text { Guo, } \\
\text { Feng, } \\
\text { Jin.[13] }\end{array}$ & $\begin{array}{c}\text { Jilani, } \\
\text { Burney, } \\
\text { Ardil. } \\
\text { [14] }\end{array}$ & $\begin{array}{c}\text { Wang, } \\
\text { Guo, } \\
\text { Feng, } \\
\text { Jin.[15] }\end{array}$ & $\begin{array}{c}\text { SFBODR } \\
(0.00004,0.00003)\end{array}$ & $\begin{array}{c}\text { SFBODR } \\
(0.00003,0.00004)\end{array}$ \\
\hline 1971 & 13055 & - & - & 13579 & - & 13055 & 13055 \\
\hline 1972 & 13563 & - & - & 13798 & - & 13563 & 13563 \\
\hline 1973 & 13867 & 13813 & 13845 & 13798 & 13745 & 13867 & 13867 \\
\hline 1974 & 14696 & 14681 & 14729 & 14452 & 14531 & 14696 & 14696 \\
\hline 1975 & 15460 & 15525 & 15412 & 15373 & 15575 & 15460 & 15460 \\
\hline 1976 & 15311 & 15189 & 15317 & 15373 & 15446 & 15311 & 15311 \\
\hline 1977 & 15603 & 15685 & 15620 & 15623 & 15555 & 15603 & 15603 \\
\hline 1978 & 15861 & 15895 & 15895 & 15883 & 15901 & 15861 & 15861 \\
\hline 1979 & 16807 & 16878 & 16786 & 17079 & 16933 & 16807 & 16807 \\
\hline 1980 & 16919 & 16839 & 16961 & 17079 & 16950 & 16919 & 16919 \\
\hline 1981 & 16388 & 16505 & 16334 & 16497 & 16601 & 16388 & 16388 \\
\hline 1982 & 15433 & 15349 & 15461 & 15737 & 15456 & 15433 & 15433 \\
\hline 1983 & 15497 & 15511 & 15497 & 15737 & 15544 & 15497 & 15497 \\
\hline 1984 & 15145 & 15026 & 15094 & 15024 & 15165 & 15145 & 15145 \\
\hline 1985 & 15163 & 15051 & 15133 & 15024 & 15187 & 15163 & 15163 \\
\hline 1986 & 15984 & 15980 & 15972 & 15883 & 15953 & 15984 & 15984 \\
\hline 1987 & 16859 & 16805 & 16805 & 17079 & 16849 & 16859 & 16859 \\
\hline 1988 & 18150 & 18246 & 18183 & 17991 & 18211 & 18150 & 18150 \\
\hline 1989 & 18970 & 18926 & 18990 & 18802 & 19077 & 18970 & 18970 \\
\hline 1990 & 19328 & 19275 & 19338 & 18994 & 19344 & 19328 & 19328 \\
\hline 1991 & 19337 & 19428 & 19346 & 18994 & 19200 & 19337 & 19337 \\
\hline 1992 & 18876 & 19046 & 18822 & 18916 & 18851 & 18876 & 18876 \\
\hline AFER & & $0.442 \%$ & $0.171 \%$ & $1.02 \%$ & $0.462 \%$ & $0.0 \%$ & $0.0 \%$ \\
\hline MSE & & 6825 & 1121 & 41426 & em, le & 0 & 0 \\
\hline
\end{tabular}

TABLE I. COMPARISONS OF DIFFERENT FORECASTING MODELS

\begin{tabular}{|c|c|c|c|c|c|c|c|}
\hline Year & Enrollments & $\begin{array}{c}\text { Feng, } \\
\text { Guo, } \\
\text { Wang, } \\
\text { Zhang.[6] }\end{array}$ & $\begin{array}{c}\text { Saxena, } \\
\text { Sharma, } \\
\text { Easo. } \\
\text { [7] }\end{array}$ & $\begin{array}{c}\text { Wang, } \\
\text { Guo, } \\
\text { Feng, } \\
\text { Jin.[8] }\end{array}$ & $\begin{array}{c}\text { Wang, } \\
\text { Guo, } \\
\text { Wang, } \\
\text { Feng.[9] }\end{array}$ & $\begin{array}{c}\text { Wang, } \\
\text { Guo, } \\
\text { Feng, } \\
\text { Zhang.[10] }\end{array}$ & 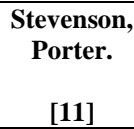 \\
\hline 1971 & 13055 & - & - & - & - & - & - \\
\hline 1972 & 13563 & 13563 & 13486 & - & 13563 & - & 13410 \\
\hline 1973 & 13867 & 13867 & 13896 & 13809 & 13867 & 13867 & 13932 \\
\hline 1974 & 14696 & 14696 & 14698 & 14610 & 14695 & 14691 & 14664 \\
\hline 1975 & 15460 & 15461 & 15454 & 15422 & 15460 & 15461 & 15423 \\
\hline 1976 & 15311 & 15312 & 15595 & 15299 & 15311 & 15311 & 15847 \\
\hline 1977 & 15603 & 15604 & 15600 & 15642 & 15603 & 15607 & 15580 \\
\hline 1978 & 15861 & 15860 & 15844 & 15901 & 15861 & 15861 & 15877 \\
\hline 1979 & 16807 & 16804 & 16811 & 16782 & 16796 & 16797 & 16773 \\
\hline 1980 & 16919 & 16920 & 16916 & 16935 & 16919 & 16920 & 16897 \\
\hline 1981 & 16388 & 16387 & 16425 & 16328 & 16388 & 16375 & 16341 \\
\hline 1982 & 15433 & 15430 & 15657 & 15362 & 15432 & 15436 & 15671 \\
\hline 1983 & 15497 & 15496 & 15480 & 15496 & 15497 & 15497 & 15507 \\
\hline 1984 & 15145 & 15143 & 15214 & 15077 & 15144 & 15136 & 15200 \\
\hline 1985 & 15163 & 15163 & 15184 & 15274 & 15163 & 15163 & 15218 \\
\hline 1986 & 15984 & 15976 & 15995 & 15966 & 15982 & 15861 & 16035 \\
\hline 1987 & 16859 & 16858 & 16861 & 16849 & 16859 & 16858 & 16903 \\
\hline 1988 & 18150 & 18150 & 17965 & 18312 & 18150 & 18154 & 17953 \\
\hline 1989 & 18970 & 18974 & 18964 & 18974 & 18970 & 18976 & 18879 \\
\hline 1990 & 19328 & 19326 & 19329 & 19236 & 19327 & 19329 & 19303 \\
\hline 1991 & 19337 & 19338 & 19378 & 19299 & 19337 & 19338 & 19432 \\
\hline 1992 & 18876 & 18872 & 18984 & 18951 & 18874 & 18766 & 18966 \\
\hline AFER & & $0.0099 \%$ & $0.3406 \%$ & $0.273 \%$ & $0.0026 \%$ & $0.085 \%$ & $0.57 \%$ \\
\hline MSE & & 7 & 9169 & 2912 & 1 & 1384 & 21575 \\
\hline
\end{tabular}

TABLE II. COMPARISONS OF DIFFERENT FORECASTING MODELS 


\section{CONCLUSIONS}

In the study of the forecasting problem of enrollments of the University of Alabama 1971-1992, the forecasting models SFBODR(0.00004, 0.00003) and SFBODR(0.00003, 0.00004) given in this paper can obtain MSE $=0$ and AFER $=0.0 \%$ (See Table I), which are already the most ideal prediction accuracy. The history of unsatisfactory prediction accuracy of fuzzy time series forecasting models is terminated. The following work is to dig out forecasting models with high accuracy to predict the unknown data.

\section{ACKNOWLEDGMENTS}

This work is supported by the Science and Technology Cooperation Project of the Academy and Government of Sanya (2016YD04, 2014YD33) and Hainan Province Nature Science Foundation Project (20156222, 714283).

\section{REFERENCES}

[1] Q. Song and B. S. Chissom, "Forecasting enrollments with fuzzy time series-Part I,” Fuzzy Sets and Systems. vol. 54, pp. 1-9, 1993.

[2] Q. Song and B. S. Chissom, "Fuzzy series and its models," Fuzzy Sets and Systems. vol. 54, pp. 269-277, 1993.

[3] Q. Song and B. S. Chissom, "Forecasting enrollments with fuzzy time series-Part II,” Fuzzy Sets and Systems. vol. 62, pp. 1-8, 1994.

[4] Wang Hongxu and Wu Zhenxing, "Preliminary Theory of Set SDR of Fuzzy Time Series Forecasting Model,” 2016 International Conference on Mathematical, Computational and Statistical Sciences and Engineering (MCSSE2016). pp. 261-265, 2016.

[5] Wang Hongxu and Wu Zhenxing, "Preliminary Theory of Set DR of Fuzzy Time Series Forecasting Model,” 2016 International Conference on Mathematical, Computational and Statistical Sciences and Engineering (MCSSE2016). pp. 256-260, 2016

[6] Hao Feng, Jianchun Guo, Hongxu Wang*, and Fujin Zhang, “A modified method of foreecasting enrollments based on fuzzy time series," 2014 2nd International Conference on Soft Computing in Information Communication Technology (SCICT2014). The AuthorsPublished by Atlantis Press, pp. 176-179, 2014.

[7] Preetika Saxena, Kalyani Sharma, and Santhosh Easo, "Forecasting enrollments based on fuzzy time series with higher forecast accuracy rate,” Int. J. Computer Technology \& Applications. vol. 3 (3), pp. 957961, 2012.

[8] Wang Hongxu, Guo Jianchun, Feng Hao, and Jin Hailong, "A new forecasting model of fuzzy time series," Applied Mechanics and Materials. vol. 678, pp. 59-63, 2014 [2014 3rd International Conference on Mechatronics and Control Engineering (ICMCE 2014). 2014].

[9] Hongxu Wang, Jianchun Guo, Hui Wang, and Hao Feng*, “A fuzzy time series forecasting model based on yearly difference of the student enrollment number,” 2014 2nd International Conference on Soft Computing in Information Communication Technology (SCICT2014). The Authors- Published by Atlantis Press, pp. 172-175, 2014

[10] H. X. Wang, J. C. Guo, H. Feng, and F. J. Zhang, "A new model of forecast enrollment using fuzzy time series," 2014 International Conference on Education Management and Management Science (ICEMMS 2014). Tianjin, China, pp. 95-98, 2014.

[11] Meredith Stevenson and John E. Porter, "Fuzzy time series forecasting using percentage change as the universe of discourse," Proceedings of World Academy of Science, Engineering and Technology. vol. 55, pp. 154-157, 2009.

[12] HongXu Wang, JianChun Guo, Hao Feng, and HaiLong Jin, "A fuzzy time series forecasting model based on data differences," 1 ICT IN EDUCATION. Frontiers in Computer Education. pp. 15-18, 2014 [2nd International Conference on Frontiers in Computer Education (ICFCE2014). Wuhan, China, 2014].
[13] Wang Hongxu, Guo Jianchun, Feng Hao, and Jin Hailong, “An improved forecasting model of fuzzy time series,” Applied Mechanics and Materials. vol. 678, pp. 64-69, 2014 [2014 3rd International Conference on Mechatronics and Control Engineering (ICMCE 2014). 2014].

[14] T. A. Jilani, S. M. A. Burney, and C. Ardil, "Fuzzy metric approach for fuzzy time series forecasting based on frequency density based partitioning," Proceedings of World Academy of Science, Engineering and Technology. vol. 34, pp. 333-338, 2007.

[15] HongXu Wang, JianChun Guo, Hao Feng, and HaiLong Jin, “A fuzzy time series forecasting model based on percentages," 1 ICT IN EDUCATION.Frontiers in Computer Education. pp. 11-14, 2014 [2nd International Conference on Frontiers in Computer Education (ICFCE2014). Wuhan, China, 2014].

[16] Tahseen A. Jilani, S. M. Aqil Burney, and C. Ardil, "Multivariate high order fuzzy time series forecasting for car road accidents," World Academy of Science, Engineering and Technology. vol. 1, pp. 288-293, 2007. 